\title{
Editorial
}

\section{Pharmaceutical free trade: will it be fair?}

\author{
John S. Dowden, Editor, Australian Prescriber
}

Key words: drug industry, drug regulation, Pharmaceutical Benefits Scheme.

(Aust Prescr 2004;27:54-5)

Australia and the USA concluded a free trade agreement in February 2004. ${ }^{1}$ The USA has negotiated duty-free access for all its farm exports and $99 \%$ of its manufactured goods.

An issue of concern in the negotiations was the Australian Pharmaceutical Benefits Scheme (PBS). As the PBS covers the whole community, the Australian Government has a strong bargaining position when it comes to negotiating drug prices. Combined with policies such as reference pricing, this has resulted in Australia having low drug prices relative to most other developed nations.

It has been argued that the current Australian system reduces the profitability of the pharmaceutical industry. As many drug companies are based in the USA they could be expected to hope that the free trade agreement would improve their fortunes in Australia. Whether or not the local pharmaceutical industry will benefit to the same degree as the US companies is unclear.

The pharmaceutical part of the agreement (Annex 2-C) does not appear to contain any drastic changes, but it is open to interpretation. The agreed principles are focused on timely access to innovative pharmaceutical products. This means new drugs must be expeditiously evaluated. There is no suggestion at this stage that the Therapeutic Goods Administration (TGA) will automatically approve drugs which have already been

\section{In this issue...}

The free trade agreement between Australia and the USA may have benefits for both countries, but the impact on pharmaceuticals is unclear. Will Australia have earlier access to drugs such as the thiazolidinediones or will there be more work for the advertising watchdogs?

Beneficial treatments do not have to be new and expensive. For example, Geoff McColl tells us glucosamine can help people with arthritis of the knee.

New problems can arise with older drugs. Hester Wilce explains why temazepam gelcaps have been withdrawn from Australia, and Greg Roberts reminds us how to use thyroxine correctly. 
manner supportive of the 'right to protect public health and, in particular, to promote access to medicines for all'. ${ }^{3}$ The

US-Australia agreement does not mention equity of access or the quality use of medicines.

The details of the agreement will probably depend on the Medicines Working Group, which will be established 'to promote discussion and mutual understanding of the issues'. It is unknown if these discussions will be secret, but the only members of the Medicines Working Group will be officials from federal government agencies.

If the official line is that there will be no changes to the PBS, then why were pharmaceuticals included in the agreement? The USA has a legislative requirement for negotiations 'to achieve the elimination of government measures such as price controls and reference pricing which deny full market access for United
States products'. ${ }^{4}$ Is the US-Australia agreement an exception to this rule? If it is not, inclusion of pharmaceuticals in the agreement could eventually prove to be a costly mistake with potentially adverse consequences for public health.

\section{References}

1. Department of Foreign Affairs and Trade Australia - United States FreeTrade Agreement. Canberra: Department of Foreign Affairs and Trade; 2004.

http://www.dfat.gov.au/trade/negotiations/us_fta/text/ [cited 2004 May 14]

2. Vitry A. Is Australia free from direct-to-consumer advertising? Aust Prescr 2004;27:4-6.

3. World Trade Organization. Declaration on the TRIPS agreement and public health. Geneva: World Trade Organization; 2001.

4. Trade Act of 2002 (USA). Section 2102.

\section{Letters}

Letters, which may not necessarily be published in full, should be restricted to not more than 250 words. When relevant, comment on the letter is sought from the author. Due to production schedules, it is normally not possible to publish letters received in response to material appearing in a particular issue earlier than the second or third subsequent issue.

\section{Are new drugs as good as they claim to be?}

Editor, - It was disappointing to read that there are still people questioning the gastrointestinal safety and cost-effectiveness of the COX-2 inhibitors (Aust Prescr 2004; 27:2-3). It is even more disappointing when this opinion is referenced to a single non-systematic, heterogenous review article (that is, evidence level 5), which misrepresents the body of evidence in two important ways.

The review claims that non-steroidal anti-inflammatory drugs (NSAIDs) have minimal benefit against which to compare their adverse events. This is based on a very selective use of analgesic data from the literature (which still showed a significant difference to placebo). An alternative view is that NSAIDs are the mainstay of therapy worldwide for the symptomatic relief of arthritis and occupy the first five top rankings for analgesics on the Oxford pain relief table because of their clinical benefits. ${ }^{1}$ This is backed by clinical trials where both COX-2 inhibitors and traditional NSAIDs showed statistically and clinically different efficacy to placebo in arthritis. $2,3,4,5$

The article by Wright also states that there is no evidence for reduced gastrointestinal damage from COX-2 inhibitors. He bases this opinion on a single flawed study (CLASS) that had a statistical power of about $45 \%$ (that is, less than a $50 \%$ chance of detecting any real differences). ${ }^{6}$ He neglects to mention the wealth of other data from adequately powered studies that show a significant difference in safety and tolerability between celecoxib and the non-specific NSAIDs. $7,8,9,10,11,12,13$
If the COX-2 inhibitors did not represent a cost-effective treatment then they would not be listed on the Pharmaceutical Benefits Scheme. The Pharmaceutical Benefits Advisory Committee makes this decision based on evidence, not opinion.

\section{Dr Simon McErlane}

Medical Director

Pfizer Global Pharmaceuticals

Pfizer Australia

\section{References}

1. Oxford league table of analgesics in acute pain. http://www.jr2.ox.ac.uk/bandolier/booth/painpag/Acutrev/ Analgesics/Leagtab.html [cited 2004 May 14]

2. McKenna $F$, Borenstein $D$, Wendt $H$, Wallemark $C$, Lefkowith JB, Geis GS. Celecoxib versus diclofenac in the management of osteoarthritis of the knee. Scand J Rheumatol 2001;30:11-8.

3. Gibofsky A, Williams GW, McKenna F, Fort JG. Comparing the efficacy of cyclooxygenase 2-specific inhibitors in treating osteoarthritis: appropriate trial design considerations and results of a randomized, placebo-controlled trial. Arthritis Rheum 2003;48:3102-11.

4. Simon LS, Weaver AL, Graham DY, Kivitz AJ, Lipsky PE, Hubbard RC, et al. Anti-inflammatory and upper gastrointestinal effects of celecoxib in rheumatoid arthritis: a randomized controlled trial. JAMA 1999;282:1921-8.

5. Weisman MH. Double-blind randomized trial of diclofenac sodium versus placebo in patients with rheumatoid arthritis. Clin Ther 1986;8:427-38. 